DE92 002678

\title{
EASI: AN ELECTRONIC ASSISTANT FOR SCIENTIFIC INVESTIGATION
}
A. Schur
D. F. Feller
D. M. DeVaney
J. J. Thomas
M. L. Yim

September 1991

\author{
Presented at the \\ Human Factors Society \\ Annual Meeting \\ September $2-6,1991$ \\ San Francisco, California
}

Work supported by

the U.S. Department of Energy under Contract DE-ACO6-76RLO 1830

\author{
Pacific Northwest Laboratory \\ Richland, Washington 99352
}

\section{DISCLAIMER}


EASI: AN EIECTRONIC ASSISTANT FOR SCIENTIFIC INVESMIGAFION

Anne Schur, Dave Feller, Mike DeVaney, Jim Thomas, and Morgan Yim

Pacific Northwest Laboratory

P.O. Box 999

Richland, Washington 99352

\begin{abstract}
Although many automated tools support the productivity of professionals (engineers, managers, architects, secretaries, etc.), none specifically address the needs of the scientific researcher. The scientist's needs are complex and the primary activities are cognitive rather than physical. The individual scientist collects and manijulates large data sets, integrates, synthesizes, generates, and records infoimation. The means to access and manipulate information are a critical ceterminant of the performance of the system as a whole. One hindrance in this process is the scientist's computer environment, which has changed little in the last two decades. Extensive time and effort is demanded from the scientist to learn to use the computer system. This paper describes how chemists' activities and interactions with information were abstracted into a common paradigm that meets the critical requirement of facilitating information access and retrieval. This paradigm was embodied in EASI, a working prototype that increased the productivity of the individual scientific researcher.
\end{abstract}

\title{
INTRODUCTION
}

Systematic domains (Winograd and Flores, 1987) can support the productivity of numerous professionals. However, none specifically address the needs of the scientific researcher. Scientific understanding is developed incrementally from individual insights.

Scientists needs are complex (Bair, 1990) and their primary activities are cognitive, e.g., analytical problem solving, rather than physical. scientists collect and manipulate large data sets, integrate, synthesize, generate, and record information. The scientists means to access and manipulate information are a critical determin-ant of the performance of the system as a whole. One hinderance in this process is the scientist's computer environment which has changed little in the last two decades. One of the weaknesses of the scientists' comput-ing environment is that it demands extensive time and effort, to simply learn to use the computer system. To improve scientific productivity, better methods of interacting with computing tools and managing information is needed. This will

allow the researcher to focus on addressing scientific questions as opposed to deciphering computer technology.

This paper describes a tool that leverages the entities scientists are familiar with and facilitates information access and retrieval. It provides a case study of the methodology, design concepts, and evaluation techniques used to create the systematic domain for scientific researchers.

\section{AP P ROACH}

Engineering the system for usability (Whiteside et al, 1988) was critical to the success of the tool. Four strategies were employed to focus attention on users and place them in a primary developer role: 1) forming a multidisciplinary system development team, 2) conducting Interactive process Modeling (IPM) sessions, 3) prototyping, and 4) capturing users' evaluations of the prototype in real-time. 
The team included 2 computational chemists and experts from information management, data visualization, artificial intelligence, and human factors.

\section{IPM Session}

Team members met in a setting where all could interact without external interruptions over an extended period of time. The outcome of this process was a shared vision and starting point for system design. A collaboratively developed description of chemists' interactions with scientific information and associated activities was the product. This information provided the first set of system requirements.

\section{Rretetyping}

The prototype tool provided a working model and living document of the requirements for a system envisioned by scientists. The tool was used iteratively.

\section{en-line capture of User comments}

A tool was developed to capture, on-line and in real time, comments from the user during system evaluation. This tool, analogous to a paper "post-it" note, allows the user to mark and make comments about the system from its behavior to the display format. The comments are placed where the system behavior occurs and the context of that event is captured.

The IPM sessions provided the framework upon which to begin our efforts. Initially our attention focused on the metaphor of a laboratory notebook to support the scientific process. User requirements were identified. Table-1 summarizes these with scme of the capabilities that were embodied into EASI. As the session progressed, the laboratory notebook metaphor evolved to an Electronic Assistant for Scientific Investigation (EASI).

Table-1: EASI Requirements and Associated Features

\begin{tabular}{|c|c|}
\hline $\begin{array}{l}\text { USER } \\
\text { REQUIREMENTS }\end{array}$ & FEATURES \\
\hline ORGANIZE & $\begin{array}{l}\text { CREATE NOTEBOOKS, BOOKMARKS, } \\
\text { SECTION DIVIOERS, USER-DRIVEN } \\
\text { PLACEMENT OF NOTEBOOKS AND } \\
\text { INFORMATION. }\end{array}$ \\
\hline ASSISTANCE & $\begin{array}{l}\text { ADMINISTRATIVE, SCHEDULING, } \\
\text { SEARCH ANC. COMPUTATIONAL } \\
\text { PROGRAM ASSISTANTS. }\end{array}$ \\
\hline LINKING & $\begin{array}{l}\text { HYPERLINK, METALINK, APPLICATION } \\
\text { PORTALS, REFERENCE ICONS. }\end{array}$ \\
\hline $\begin{array}{l}\text { SUPERVISORY } \\
\text { CONTROL }\end{array}$ & $\begin{array}{l}\text { RUN MONITOR - data visualization, } \\
\text { sUmmary status wIndow. }\end{array}$ \\
\hline $\begin{array}{l}\text { EASY } \\
\text { NAVIGATION \& } \\
\text { ORIENTATION }\end{array}$ & $\begin{array}{l}\text { OFFICE AND NOTEBOOK GRAPHICS, } \\
\text { FEEDBACK, ACTIVITY TRAIL, MULTIPLE } \\
\text { ENTRY POINTS, AND BOOK CONTROL. }\end{array}$ \\
\hline COMMENTS & NOTEPAD AND ANNOTATION TOOL. \\
\hline
\end{tabular}

\section{EASI DESCRIPTION}

The capabilities necessary to facilitate the scientific process are built 
around the Laboratcry notebook. EASI users access lab notebcoks through. their "office" (Eigure-1). The office provides bookshelves, desk, takit, books, and notebooks. The chemist can point to any book or notebook to open and arrange them anywhere within the office, and bring new books in to the office. Books may also be opened by accessing pop-up menus. Other functions allow books to be renamed, saved, archived (removed from the visual office environment), and closed.

Once a book is opened many features are available to the scientist for recording and organizing work in the notebook (Figure-2). A chemist may place bookmarks and section dividers, and add pages sequentially. The system also offers a number of recording options. These options reside outside and are located around the notebook to give a standard set of capabilities (e.g. hypertext features, annotation, access to software application tools) regardless of where the chemist is performing work (e.g. office, run

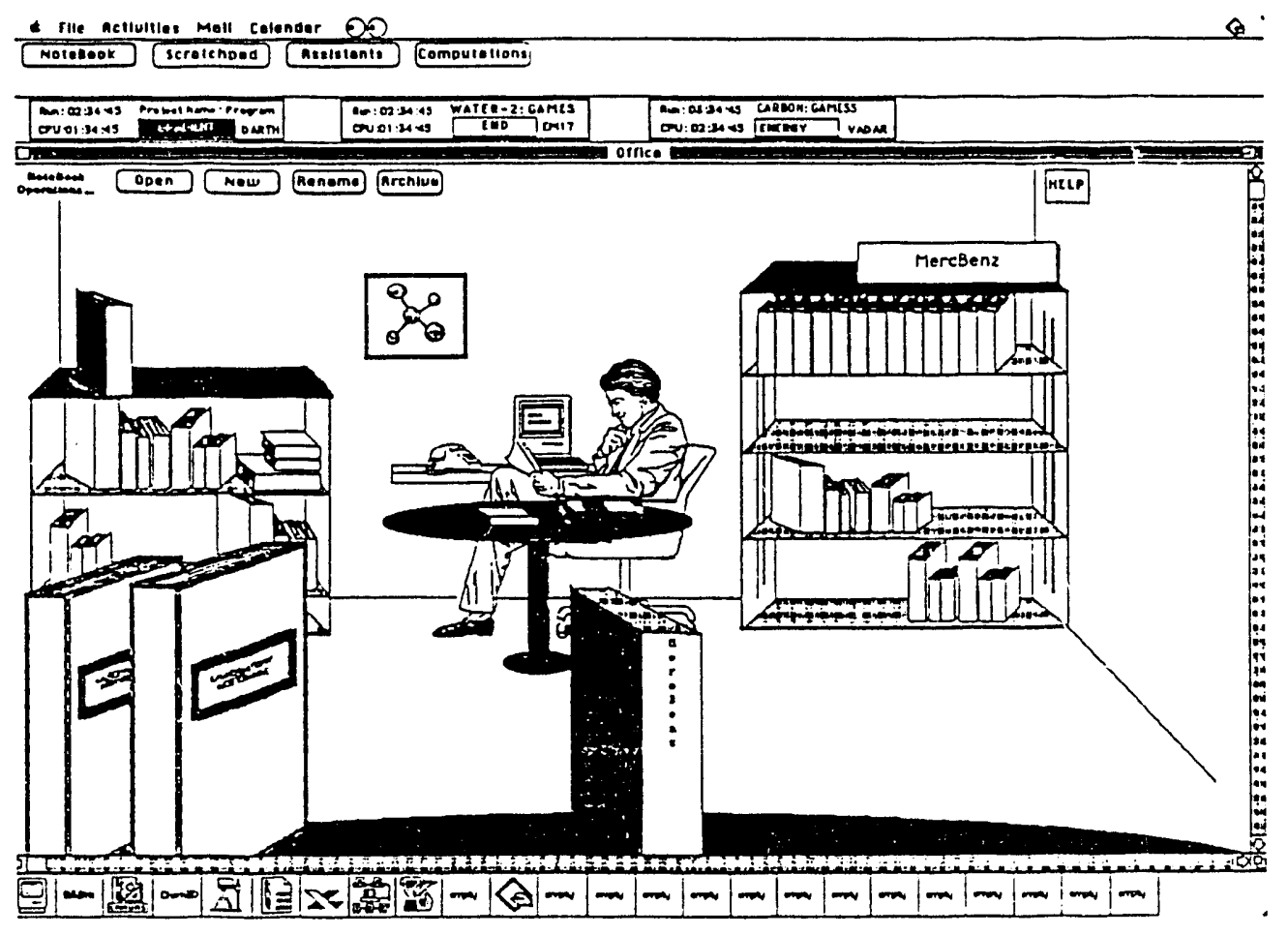

Figure-1 -: The office

monitor, scratch pad). Chemists can also annotate any work contained in the system.

\section{SOME DESIGN PRINCIPIES USED FOR EASI}

Many design principles were used to create EASI. None are new. However, some appeared to be of critical value in providing the chemist with perceived complete and instant direct control of information access, storage, manipulation, and exploration. These are briefly described within the context of EASI.

\section{Hypertext}

Hypertext concepts (Nielson, 1990) were used to form links between information and to facilitate information recording. Users distinguished between two types of linking. The ability to link to programs and information residing locally (hyperlink) and remotely (metalink). Metalink provides tine ability to record information by reference. Here the chemist can link to material outside the notebook, e.g., large data sets, literature search 
material outside the notebook, e.g., large data sets, literature search results, networks, application tools: visualization packages, anc electronic mail. Metalink offers several advantages. Large data sets are not stored within the notebook, but are accessed in their entirety when required. User's choice of specific instances of application types is enabled this way. Unique capabilities of other applications can be used without having to recreate them within EASI. Further, metalink facilitates documentation control between collaborative researchers.

\section{Eigure/Ground}

The visual system's ability to form figure/ground relationships was used to reduce the need to arrange information hierarchically. The simplified display made it possible to present more needed information at one time. Figure-1 illustrates the design to emphasize where the scientist can place their most frequently used materials while the surrounding area provides visual organization of items in this office. In Figure-2, the notebook is the background where information is placed and organized. In both examples, a third visual layer

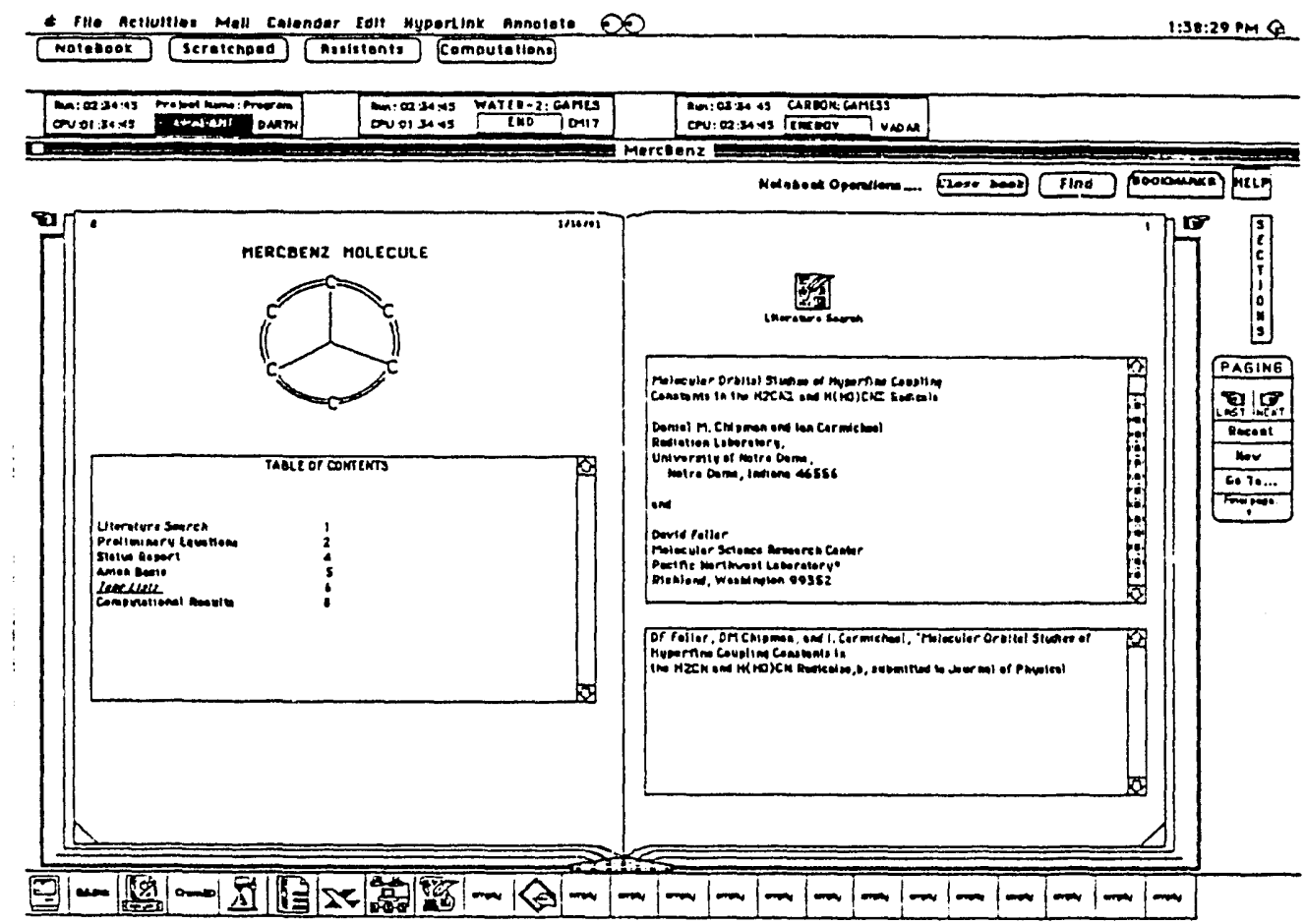

Figure-2: The Notebook

resides in the background. This layer contains the supporting controls and other processes the scientist needs to have immediately accessible. Window borders organize the relationships between functions.

\section{Spatial cues}

Many people remember where they put items based on location in space. The graphical interface enables spatial cues to be used to facilitate the location of items, i.e., access. The visual cues used to facilitate recall were based on common practice. The office and notebook (Eigures 1 and 2) are examples. In both cases, the chemist is afforded the opportunity to organize information according to their own preferences. 
Multiple pathways and entry points provide access to information easily. For example, accessing information within the notebook can be achieved numerous ways using bookmarks and sections, direct page access and paging. Information linked to external sources can be accessed from appropriate lists or directly via icons. These icons also provided a mnemonic for referenced abstract entities and technical artifacts. Any kind of stored entity - a software tool, a specific file, could be assigned an application portal. clicking on a portal gives direct access to the selected entity. Running theoretical chemistry computational programs can be assessed directly via the Run Monitor option. Within this work space chemists can explore and monitor the results of a specific computation in real time.

Medal eperations

The ability to move seamlessly from one kind of transaction to another was provided to give literal and perceived instant access to and selection of desired entities of information, application tools, and computational results. The removal of modal operations enabled the chemist to focus attention on science rather than aspects of the computer environment in which they were performing their task. Removing modal operations from the human-computer dialogue proved a challenge in the selected prototyping environment.

\section{DISCUSSION}

The ability to capture, on-line and in real-time, comments from the user as they worked with the prototype proved valuable. It was possible to precisely identify where the users had difficulty accessing and manipulating information and to find the cause of the problem. We could also uncover inconsistencies in the dialogue structure. The chemists made it very clear when their expectations were not met. Many times they provided an explanation about the encountered problem and suggested solutions. The prototype became the primary tool used to define our requirements and an invaluable vehicle to test and articulate team ideas. The prototype was meant to serve as a model of the chemists requirements. The success of this model became apparent when some chemist used this model as a working prototype.

Two major functions to support the scientific process were provided by EASI: 1. A repository for information selected by the scientist and 2 . A unifying means to easily manipulate, explore, store, and access the wide variety of computer programs and information necessary for scientific research and other daily activities. The ownership of EASI was gained by the chemists thanks to the processes employed to define and evaluate the system.

\section{CONCIUSIONS}

We have sufficiently abstracted the chemists actions and their interactions with information into a common paradigm. The computer as a structured dynamic communication medium can be leveraged to create domains oriented to the structure of the chemists' perceptions memory strategies, and behaviors despite the complexity of the computing world they must interact with. This paradigm is proving to be extensible to other technical areas laboratory automation, environmental health policies and regulations, and online documentation. These users require access to huge amounts of data, numerous data bases, and software applications to perform their work. Like the chemist, they must also explore, integrate, synthesize, ant generate information. EASI appears to facilitate this process. 
The keyboard and mouse input methods limit the scientist's ability to make spontaneous calculations and drawings into the system. We plan to extend the input capabilities to accept landwriting and to enhance the scratch pad capabil-ities. Although the adopted paradigm facilitates the access of information the ability to search and browse material has not been addressed. We plan to explore this area with emphasis on semantic and conceptual search.

\section{REEERENCES}

Bair, R., (Ed.), (1990). Graphical User Interfaces in computational Chemistry Draft Workshop Report PNL-SA-18847.

Nielson, J. (1990). Hypertext and HypermedAaademic Press.

Winograd, T., Flores, F. (1987). Understanding Computers and Cognition, Addison Wesley.

Whiteside, J., Bennett, J., Holtzblatt, K. (1988). Usability Engineering: Our Experience and Evolution. In M. Hollender, (Ed.), Handbook of Human-Computer Interaction Elsevier North-Holland, 791-817. 

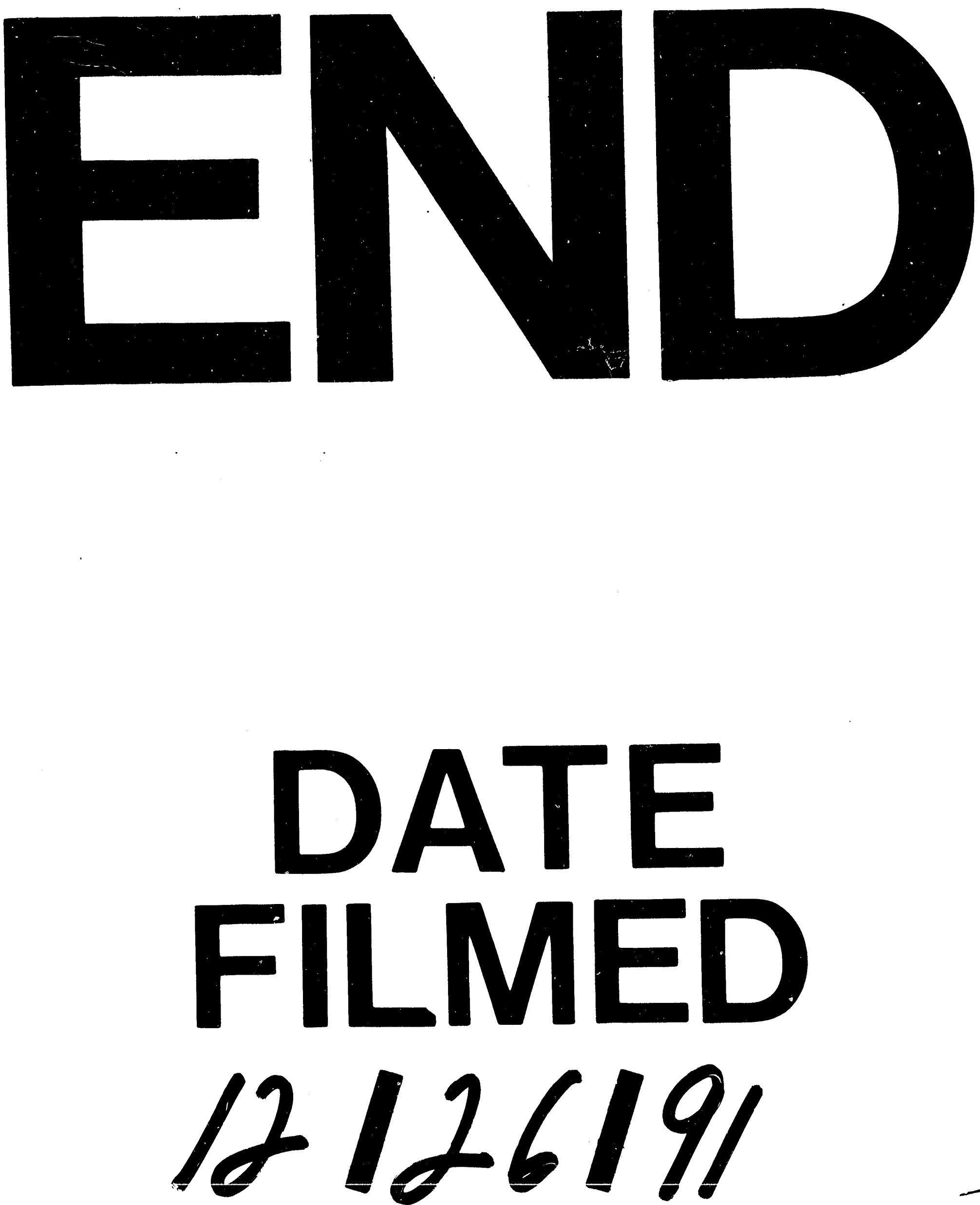
